\title{
Sexualidad femenina y el estatuto del niño en la práctica clínica
}

Female sexuality and the status of the child in clinical practice

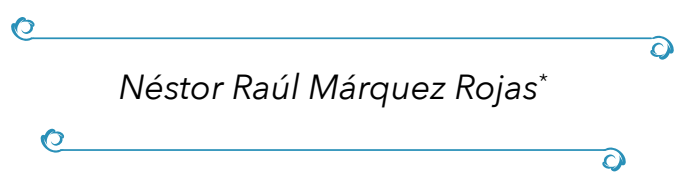

Recibido: $10.02 .2019 \bullet$ Arbitrado: $12.03 .2019 \bullet$

Aprobado: 25.04.2019

Psicólogo, Universidad de San Buenaventura. Magister en Psicoanálisis, Universidad de Antioquia. Estudiante de Doctorado en Ciencias Sociales, Universidad Pontificia Bolivariana, Medellín, Profesor de tiempo completo, facultad de psicología Institución Universitaria de Envigado, nrmarquez@correo.iue.edu.co

\section{Resumen}

La conexión entre sexualidad femenina y la práctica clínica con niños se deja entrever tempranamente en la historia del psicoanálisis, Freud señala este vínculo a partir de sus estudios sobre la teoría fálica - las vicisitudes de la resolución edípica tanto para el niño como para la niña-, tesis de trabajo que corroborará a partir de la síntesis de los distintos casos clínicos. El objetivo primordial del presente artículo de revisión es plantear a partir de la teoría del Edipo y sus nexos con la sexualidad femenina, las directrices de la práctica clínica con niños desde la mirada de Freud y Lacan. De otro lado, se utilizó como metodología de trabajo el enfoque cualitativo, nivel descriptivo y tipo bibliográfico. Y, se realizó una lectura tanto a nivel intratextual como intertextual de fuentes primarias relacionadas con el tema de trabajo.

Palabras clave: práctica clínica, sexualidad femenina, complejo de Edipo, psicoanálisis, madre, niño. 


\section{Abstract}

The connection between female sexuality and clinical practice with children is glimpsed early in the psychoanalysis history, Freud points out this link from his studies on the phallic theory - the vicissitudes of the oedipal resolution for both the boy as the girl-, work thesis that will corroborate from the synthesis of the different clinical cases. This main objective of this revision papers is to propose some addreses to the clinic practice with children since a Frudian and Lacanian point of view based on Edipo's theory and its relation with female sexuality. Otherwise, a qualitative, descriptive and bibliographic approach was carried out in the methodology. Also, a reading of primary sources highly connected to this topic, in both intratextual and intertextual levels, was done.

Keywords: clinic practice, female sexuality, Oedipus complex, psychoanalysis, mother, child.

\section{Introducción}

El presente ensayo está orientado en el campo de la clínica y tiene como propósito fundamental anudar los ejes específicos sobre los cuales gira el psicoanálisis en general, y la practica con niños en particular, tomando como eje de análisis, él estatuto del niño en la práctica clínica y sus nexos con la sexualidad femenina. Muy tempranamente Freud a través de su trabajo "Tres ensayos para una teoría sexual" (1907), articula los ejes que orientan la práctica clínica en general y al mismo tiempo, este nexo es lo decisivo en el psicoanálisis con niños.

En su trabajo "La sexualidad femenina" (1921) - un recorrido a través de la teoría fálica-, Freud nos enseña acerca de las vicisitudes que tiene que sortear el sujeto femenino en relación al núcleo edipico y la castración. La sexualidad humana según el psicoanálisis no se rige por el instinto sino por el fantasma que contiene una estructura de carácter perverso. Así la sexualidad en el niño, en términos de Trieb, desde "Tres ensayos..." está articulada con la perversión y, después, con el fantasma.

El estatuto de la sexualidad femenina tal como lo destaco Freud, deja ver muchos puntos enigmáticos, y esto porque el Edipo en la niña se concibe de manera contraria al Edipo en el niño. Freud a través del estudio de casos de histeria femenina, llega a la deducción de que, "algo de lo no concluido es especifico de la sexualidad femenina". En su reflexión "Sobre la sexualidad femenina" (1921), plantea una simetría entre hombres y mujeres respecto de 
la premisa fálica. Propone para la mujer tres orientaciones del desarrollo: una la inhibición sexual o la neurosis, la otra, la alteración del carácter en el sentido de la masculinidad, y la tercera la feminidad normal, vía de la ecuación simbólica pene $=$ hijo .

A partir de estas tres orientaciones que propone Freud, se rastrea el nexo: neurosis infantil y sexualidad femenina. Para el desarrollo de este texto se partió de la elaboración axiomática de Freud, en el sentido de que, "toda neurosis del adulto se construye sobre las reliquias de una neurosis infantil" Silvestre (1987). Un caso prínceps de Freud, el estudio del "Hombre de los lobos" (1918), ejemplifica ésta elaboración. Así mismo, a través del análisis de un caso de histeria femenina, "Dora" (1907); y un caso de obsesión masculina, "Hombre de las ratas" (1910), se puede palpar el nexo entre neurosis infantil y sexualidad femenina. Destacando particularmente en uno y otro caso una versión posible del final de análisis, así se tendría que: "tanto para los hombres como para las mujeres el final de análisis se presenta como un callejón sin salida, y esto porque el encuentro con la feminidad puede constituir un encuentro con lo real. Encuentro con lo real, en tanto lo que se pone en juego para el sujeto es "la realidad inconsciente del significante falo" (Miller, 1988).

Estas reflexiones sobre el Edipo en la mujer tratan fundamentalmente de la falta femenina, de la división que produce el objeto-niño en tanto dicha falta se trata de resarcir ya bien por la vía de la maternidad, o por vía alterna que implica un goce suplementario ligado a la mujer y no a la madre. Esta cuestión es preliminar a todo tratamiento posible con los niños: "en la clínica se debe tener en cuenta que el niño tiene una relación especial con la madre, y que la madre es ante todo una mujer". La anterior elaboración clínica surge a propósito del estudio que realiza Jacques Lacan en el seminario "La relación de objeto" (1956), en donde pone en el centro de la problemática infantil la relación madre-niño. Lacan hace hincapié en el hecho de que, "todo síntoma infantil tiene que ver con la subjetividad de la madre, en tanto que la madre es una mujer" (Solano, 1998:150). Todas las directrices de la clínica con niños se orientan a partir de la posición que ocupa el niño en relación con la posición femenina de la madre. Y, ello porque la madre, como mujer tiene una relación especial con la falta, de un objeto primordial, que desde el trabajo sobre la "sexualidad femenina "Freud (1921), denominó como falo. Con este objeto, la mujer tiene una relación fundamental y es con este objeto que el niño va a introducirse en la subjetividad de la madre.

La anterior reflexión lleva a plantear los nexos entre sexualidad femenina, en términos de la metáfora del Nombre-del-Padre y las versiones o modalida- 
des del final de análisis con niños. De otro lado, se realiza una reflexión desde el punto de vista de la teoría fálica y el -objeto a- sobre las versiones del final de análisis. Y, particularmente se desarrolla la conexión: Sexualidad femenina, y el estatuto del niño en la práctica clínica. Sobre estos dos ejes fundamentales, sexualidad femenina en términos del deseo de la madre (DM); y la metáfora del niño, objeto sustituto, Ersatz (sustituto) del deseo materno, se pueden orientar las distintas versiones del final de análisis en la clínica con niños. $\mathrm{Y}$, es acá que cobra valor la pregunta que orienta el presente escrito, esto es: ¿Cuál es el estatuto del niño en la práctica clínica?

Jacques Alain Miller (1988), insiste en que, "cada análisis de niños implica verificar como el sujeto - niño (Sn) se articula en relación al sujeto - femenino (Sf) con su falta fálica, y como se inscribe el niño en esa relación". Esto implica exponer las consecuencias clínicas de la sexualidad femenina para cada sujeto, en la medida en que cada uno es hijo de una madre. Por ello el tema más importante para trabajar en la clínica con niños, es el tema de la sexualidad femenina.

A partir de las elaboraciones sobre la metáfora fálica en Freud y la conceptualización del objeto $\boldsymbol{a}$ en Lacan, se pueden orientar dos versiones del final de análisis con niños: una en donde el niño tenga una versión del falo- instante de la sexuación del infantil sujeto -; otra en la cual el niño tenga una versión del objeto $\boldsymbol{a}$, construcción de un fantasma que garantice que su cuerpo no será condensador del goce materno. Y, por último, "el final de análisis con niños implica un tratamiento del síntoma y su implicación en el fantasma". Acá hay una doble doctrina sobre la práctica clínica con niños: según el análisis se conciba como medio para alcanzar una mediación simbólica incluso subjetiva del niño en el fantasma, o como operación de desciframiento del goce del síntoma.

\section{Metodología}

Para la realización del presente artículo, se utilizó el enfoque cualitativo, nivel descriptivo y método bibliográfico, el cual tiene por propósito, según Alfonso (1995), indagar, recolectar, organizar, analizar e interpretar información o datos en torno a una determinada temática. Este tipo de trabajo se articula dentro de las técnicas de investigación documental, las cuales se refieren por lo general a las fuentes de información utilizadas en la investigación y se le denominan genéricamente como "unidades conservatorias de información", esto es, se trata de documentos, bibliografías, publicaciones, estados del arte, estados del conocimiento, y textos de autores de primera 
mano, cuya función es la de almacenar o contener información. Estas técnicas de investigación documental se aplican a algunos tipos de documentos -generalmente a textos: libros, artículos en revistas y reportes de entrevistas, entre otros- (Rojas Crotte, 2011:281).

Para la elaboración del presente ensayo se seleccionaron los trabajos originales de algunos autores del campo del psicoanálisis contemporáneo Miller (1998), Laurent (1999), Cottet (1998), Solano (1998) y Silvestre (1987); e, igualmente, se revisaron autores clásicos como Freud (1907, 1910, 1911, 1919), Winnicott (1965), y Lacan (1953, 1955, 1956, 1957, 1964). Esta revisión se llevó a cabo a través de la disciplina del comentario de texto. La lectura intratextual es un primer tiempo de lectura que aspira a investigar un texto, para intentar establecer, sólo desde el texto mismo, lo que éste dice. En tanto que, la lectura intertextual, comprende el segundo tiempo de la lectura, en el cual se pretende cotejar y someter a discusión unidades de análisis (párrafos, conceptos, enunciados, etc.) de dos o más textos, de uno o varios autores (Pérez, 1998:239).

Como criterios de selección de los respectivos trabajos, se tuvo en consideración el "criterio de pertinencia", esto es, que las fuentes consultadas deben ser acordes con el objeto de investigación y con sus respectivos objetivos, en tanto que estos aportan conocimientos, enfoques, teorías, conceptos y experiencias significativas para fundamentar la realización del artículo en cuestión. De otro lado, se tomó en consideración el "Criterio de actualidad", el que, a su vez, implica que las fuentes consultadas deben ser lo suficientemente actuales como para asegurar que reflejen los últimos desarrollos de la materia, o disciplina objeto de tratamiento. Por último, se tuvieron en consideración los aspectos éticos relacionados con los derechos de autor y las respectivas normas de citación exigidas por la APA (2006).

\section{Desarrollo del tema}

\section{La sexualidad femenina: recorrido desde el punto de vista de la teoría fálica}

Abordar un estudio sobre la sexualidad femenina a partir de los escritos freudianos implica necesariamente un desarrollo de los conceptos de Edipo y de castración, en otras palabras, nos remite a la teoría fálica. El misterio que esconde la feminidad interroga a Freud a lo largo de muchos años, por ello, es conveniente señalar que las siguientes elaboraciones conceptuales obedecen a distintos momentos históricos que la obra freudiana ofrece como un intento 
por descifrar ese enigma que encierra la sexualidad femenina. Veamos a continuación, el desarrollo histórico de la obra de Freud en torno a la denominada teoría fálica y sus nexos con la sexualidad femenina.

Primer momento: (1905-1923). El desarrollo teórico importante se plasma en su trabajo "Tres ensayos para una teoría sexual" (1907). Freud declara que el primer objeto sexual de un niño es el pecho materno, "el cual se vuelve paradigmático para todo vínculo de amor" (Freud, 1996:222). Tanto para el niño como para la niña la madre es el primer objeto de amor, y las primeras investiduras de objeto se producen por apuntalamiento en la satisfacción de las grandes y simples necesidades vitales. La madre es, en todo sentido activa hacia el hijo, y hasta respecto del acto de mamar puede decirse que ella da de mamar al niño cuanto que lo deja mamar de ella. Y, mientras más se aleje en el ámbito estrictamente sexual, más nítida se les volverá esa "falta de correspondencia". En 1911 en su texto "El tabú de la virginidad" destaca una diferencia del desarrollo sexual en la temprana infancia, en donde distingue una fase masculina en la niña ligada a la envidia de pene; "desde el punto de vista de la historia de desarrollo, esta fase masculina de la mujer, fase en la cual envidia al varón su pene, es más temprana y está más cerca del narcisismo originario que del amor de objeto" (p.200).

Después de estos dos importantes trabajos viene luego "Un caso de paranoia que contradice la teoría psicoanalítica" (1915), donde lo esencial estaba en la relación del vínculo de la paciente con su madre. Lo mismo podría decirse de "Sobre la psicogénesis de un caso de homosexualidad femenina" (1920). Entre uno y otro, se publicó "Pegan a un niño" (1919), que versaba casi con exclusividad sobre el desarrollo infantil de las niñas; y aquí ya hay una clara evidencia de insatisfacción con la analogía para ambos sexos. Veamos el comentario de Freud (1911), al respecto de esta articulación conceptual. La fantasía de seducción de la niña por el padre: "al fin tuve que llegar a la intelección de que esos informes eran falsos, y así comprendí que los síntomas histéricos derivan de fantasías, no de episodios reales". Y, luego agrega, ahora reencontramos la fantasía de seducción en la prehistoria pre-edipica de la niña, "pero la seductora es por lo general la madre" (Freud, 1996:112).

En 1923 con la publicación de "La organización genital infantil", "el primado del falo rige los destinos de la orientación sexual para ambos sexos". Comentemos este texto a través de Lacan (1956), en este trabajo Freud plantea como un principio la primacía de la asunción fálica. La fase fálica, etapa terminal en la primera época de la sexualidad infantil, que se termina con la entrada del periodo de latencia, es una fase típica tanto para el niño como para la niña. La organización genital da su fórmula. Los dos sexos la alcanzan. 
"La posesión o la no posesión del falo es un elemento diferencial primordial" (Lacan, 1994:98). Así, no hay realización del macho y de la hembra, hay lo que está provisto del atributo fálico y lo que está desprovisto de él, y estar desprovisto se considera equivalente a estar castrado.

Segundo momento (1924-1930). En los anteriores trabajos Freud no distingue muy bien entre la amenaza de castración y angustia de castración, puntos clave para dar cuenta de la posición sexuada del niño y de la niña. En "El sepultamiento del complejo de Edipo" (1924), establece una disimetría: para el niño el complejo de Edipo se va al fundamento a raíz de la angustia de castración, en tanto que, para la niña, la castración es toda una certeza. Así, se produce esta diferencia esencial: "la niñita acepta la castración como un hecho consumado, mientras que el varoncito tiene miedo a la posibilidad de su consumación" (Freud, 1996: 186).

En este trabajo indica Freud, que el complejo de Edipo para la niña es mucho más unívoco que para el niño. La renuncia al pene no se soportará sin un intento de resarcimiento. La niña se desliza -a lo largo de una ecuación simbólica- del pene al hijo; "su complejo de Edipo culmina en el deseo, alimentado por mucho tiempo de recibir como premio un regalo del padre, parirle un hijo" (p.186).

En 1925, Freud publica "Algunas consecuencias psíquicas de la diferencia anatómica entre los sexos", texto capital en lo que a la sexualidad femenina se refiere. Allí habla por primera vez de una prehistoria del Edipo en el varón y en la niña, lo que inevitablemente lo conduce a tratar la relación con la madre. Parte de una premisa fundamental, la madre es el primer objeto tanto para el niño como para la niña, pero acá destaca una particularidad: para el niño las visiones de los órganos genitales femeninos causan horror y esto está ligado a la amenaza de castración. Nada de esto ocurre en la niña pequeña. "En el acto se forma su juicio y su decisión. Ha visto eso, sabe que no lo tiene, y quiere tenerlo" (Freud, 1996: 271).

Desarrollemos un punto capital, para Freud con el ingreso en la fase fálica: "las diferencias entre los sexos retroceden en toda la línea ante las concordancias" ¿Qué sentido tiene esta fase fálica? Aquí el primado fálico está ligado a la organización genital. Justo antes del periodo de latencia, el sujeto infantil, masculino o femenino, llega a la fase fálica, que indica el punto de realización de lo genital. Todo está ahí, incluso la elección de objeto. Pero según Lacan, hay algo que no está, a saber, la plena relación la función genital, realmente estructurada y organizada. 
Pero Lacan (1956) va más allá de esta interpretación y nos enseña, que la función de la genitalidad no se encuentra lo suficientemente organizada, porque queda un remanente fantasmático, esencialmente imaginario, ligado al predominio del falo, en virtud del cual hay en el sujeto dos tipos de seres en el mundo: los seres que tienen el falo y los que no lo tienen, es decir, que están castrados.

De lo anterior, se puede deducir que las cualidades biológicas de la maduración genital no garantizan la posición sexuada del sujeto, en tanto no se articulen en el plano simbólico. "Por ello, se comprueba que el fantasma del falo en el nivel genital adquiere su valor en el interior de la simbólica del don" (Lacan, 1994:125). Freud insiste en ello, el falo no tiene, por una buena razón, el mismo valor para quien posee realmente el falo, o sea el niño macho, y para el niño que no lo posee, o sea el niño hembra. Según Lacan, si el niño hembra se introduce en la simbólica del don es en cuanto que no posee el falo. En la medida en que ella (la niña) faliciza la situación, es decir en cuanto se trata de tener o no tener el falo, entra en el complejo de Edipo. Para el niño, como subraya Freud, no depende de su entrada sino de su salida. Al final del complejo de Edipo, cuando realiza en determinado plano la simbólica del don, es preciso que haga don de lo que tiene. "La niña, si entra en el complejo de Edipo es porque eso que no tiene debe de encontrarlo en el complejo de Edipo" (p.125). ¿Qué quiere decir lo que no tiene? Según Lacan, está pregunta relaciona un elemento imaginario en una dialéctica simbólica. Con una particularidad, en una dialéctica simbólica lo que no se tiene existe tanto como todo lo demás. Simplemente está marcado por el signo menos.

La niña ingresa en el Edipo con el menos, como el niño entra con el más, de todos modos, tiene que haber algo para que se pueda poner un más o un menos, presencia o ausencia. Se trata entonces del falo, eso es lo que está en juego. He aquí, nos dice Freud (1924), por qué mecanismo se produce la entrada de la niña en el Edipo. Como consecuencia de la entrada de la niña en el complejo de Edipo, Freud señala la envidia del pene, subrogado de los efectos de esa operación simbólica que es la castración. En cuanto a la salida femenina del Edipo se localiza en la ecuación simbólica prefigurada pene = hijo, en donde la niña resigna el deseo del pene para reemplazarlo por un hijo, y con este propósito toma al padre como objeto de amor. "La madre pasa a ser objeto de los celos, y la niña deviene una pequeña mujer" (Freud, 1996: 274).

Lo que se juega en la dialéctica del Edipo es poder inscribir al infantil sujeto como ser sexuado, permitirle realizar el pasaje de lo natural a lo cultural. Lo que al principio es natural o biológico se traslada siempre al plano simbólico, de donde se trata la asunción subjetiva. El estudio de la sexualidad infantil 
da cuenta de la heterogeneidad del significante. Por ello la sexuación se ordena no bajo determinantes biológicos sino estructurales, el niño y la niña se relacionan con un primado fundamental: el falo. La anatomía no es punto de llegada en cuanto a la posición sexuada se refiere, todo lo contrario, es el punto de partida: ya que quien lo posee lo puede perder, y quien no lo posee lo puede llegar a ganar. Así, la angustia de castración en el niño y la envidia de pene en la niña, son las "consecuencias" de esta diferencia sexual anatómica entre los sexos.

Tercer momento (1931-1938). Freud publica su trabajo "Sobre la feminidad" (1932), allí esclarece algunas lagunas que quedaron en 1925. Para este momento histórico el Edipo ya no es el núcleo de la neurosis, sino que este lo constituye la fase preedipica en la mujer: su ligazón con la madre. Fase que a Freud siempre le pareció enigmática, "como si hubiera sucumbido a una represión particularmente despiadada” (p.228). Numerosos fenómenos de la vida sexual femenina, mal comprendidos antes, hallan su esclarecimiento pleno si se reconducen a la ligazón-madre. Un ejemplo interesante es la elección de objeto amoroso, "muchas mujeres han escogido a su marido según el modelo del padre, o lo han puesto en el lugar de este, repiten con él, sin embargo, en el matrimonio, su mala relación con la madre" (p. 232). Acá la relación recién inaugurada se complica, ya que el marido quien debía heredar el vínculo-padre termina heredando el vínculo-madre y la consabida hostilidad. Para Freud el endoso de ligazones afectivas del objeto - madre al objeto - padre constituyen en efecto, el contenido principal del desarrollo que lleva hasta la feminidad.

Así, con un primer matrimonio la mujer no logra resarcir aquella herida que dejó la castración, y, por el contrario, viene un nuevo problema, la pérdida de la virginidad con el marido se traduce en una nueva afrenta, una nueva herida narcisista, motivo de gran hostilidad. El odio hacia la madre es transferido hacia el primer marido. Por esta razón quizás, para Freud muchas mujeres se tornan frígidas y se siente desdichadas en un primer matrimonio. En el "Tabú la virginidad" (1911), complementa este punto vista, enunciando que, "tras su disolución se convierte en una mujer tierna y dócil que hace la felicidad de su segundo marido" (Freud, 1996: 201).

¿Por qué la ligazón - madre de la niña reviste un carácter hostil? Los motivos que Freud descubre para un extrañamiento son de lo más variado: omitió dotar a la niñita con el único genital correcto, la nutrió de manera insuficiente, la forzó a compartir con otro el amor materno, no cumplió todas las expectativas de amor, incitó el quehacer sexual propio y luego lo prohibió. Tras esta ojeada panorámica se demuestran motivos suficientes para justificar la final hostilidad. Es a propósito de la práctica clínica donde Freud encuentra 
estos nexos de hostilidad de la ligazón-madre, como un obstáculo al normal desarrollo sexual de la niña: La "Joven homosexual" (1920) y "Un caso de paranoia que contradice la teoría psicoanalítica" (1915), son tan solo dos ejemplos muy notorios de este tipo de vínculo.

Sobre "Un caso de paranoia..." argumenta: el vínculo madre-hija no se establece en términos de gratificación sino de hostilidad, y ello porque la madre le impone el deber de inhibir o poner en suspenso la afirmación sexual a la hija. Esta denegación del goce sexual trae sus consecuencias. Sí en el intento de alcanzar esa liberación la niña contrae neurosis, "ello se debe a la preexistencia de un complejo materno por lo general hiperintenso, y ciertamente no dominado". En todos los casos para Freud las manifestaciones de la reacción neurótica no están determinadas por el vínculo presente con la madre actual, "sino por vínculos infantiles con la imagen materna del tiempo primordial" (Freud, 1996; 267).

Y, sobre el amor apasionado de la "Joven homosexual" (1920), por la Dama comenta lo siguiente: Ella se transmudó en varón y tomó a la madre en el lugar del padre como objeto de amor. Su vínculo con la madre había sido ambivalente desde el comienzo; por eso logró con facilidad reanimar el amor temprano por la madre y, con su auxilio sobrecompensar su hostilidad presente hacia ella. Luego comenta. "Y puesto que con la madre real poco había que hacerle, de la transposición afectiva que aquí hemos descrito resultó la busca de un sustituto del cual pudiera prendarse con apasionada ternura" (Freud, 1996: 151).

1933 es el año de las "Nuevas conferencias de introducción al psicoanálisis", y allí en la conferencia número 33, "La feminidad" vuelve a tocar el punto del ingreso de la niña en el Edipo. Comienza por retomar la pregunta: ¿A raíz de que se va a pique esta potente ligazón-madre de la niña? El destino final de esta relación es habitual: está destinada a dejar sitio a la ligazón- padre. Pero en este paso del desarrollo no se trata de un simple cambio de vía de objeto. "El extrañamiento respecto de la madre se produce bajo el signo de la hostilidad, la ligazón-madre acaba en odio". El deseo con que la niña se vuelve hacia la ligazón-padre, es sin duda, originariamente, el deseo de pene que la madre le ha denegado y ahora espera del padre. "Así, el antiguo deseo masculino de poseer el pene sigue trasluciéndose a través de la feminidad consumada" (Freud, 1996: 151).

Con la transferencia de la envidia del pene por el deseo de un hijo del padre, la niña ha ingresado en la situación del complejo de Edipo. En donde según Freud (1933), se debería ver en ese deseo de pene, el deseo femenino por excelencia. La hostilidad a la madre experimenta ahora con el hijo un 
gran refuerzo, "pues deviene la rival que recibe del padre todo lo que la niña anhela de él". En estos términos se deduce que el complejo de castración en la niña prepara el complejo de Edipo en vez de destruirlo; por el influjo de la envidia del pene, la niña es expulsada de la ligazón-madre y desemboca en la situación edípica como si se tratara de un puerto (Freud, 1996:119).

Veamos con Lacan (1956), cómo el niño hembra realiza la transición por el complejo de Edipo, y como su posicionamiento frente al significante falo precipita su sexuación. Para Lacan el Edipo es ante todo una función normalizadora, en donde lo importante es conducir al sujeto a una relación objetal, por ello la elección debe de ser ante todo del tipo heterosexual. La clínica nos enseña que no basta con ser heterosexual para serlo de acuerdo con las reglas, ya que hay toda clase de heterosexualidad aparente. Para Lacan, la relación francamente heterosexual puede encubrir en ocasiones una atipia posicional que, "por ejemplo, la investigación analítica nos mostrará que se deriva de una posición francamente homosexualizada" (Lacan, 1994: 203). Por ello insiste, no basta con que el sujeto alcance la heterosexualidad tras el Edipo, sino que el sujeto niño o niña, ha de alcanzarla de forma que se sitúe correctamente con respecto a la función del padre. Este es el centro de toda la problemática del Edipo.

Para Lacan (1956), el texto de 1931 "Sobre la sexualidad femenina" es importante porque, considerado desde el punto de vista preedipico la problemática de la mujer es mucho más simple. No en vano Freud descubrió el Edipo antes de lo preedipico. Solo podemos hablar de una mayor simplicidad de la posición femenina, en el desarrollo que calificamos de preedipico, "porque sabemos por adelantado que ha de alcanzar la estructura del complejo de Edipo". Se podría decir, entonces, que la niña ha situado el falo en mayor o menor medida, o se ha acercado a él, en el imaginario en que está inmersa, "en el más allá de la madre, mediante el descubrimiento progresivo que hace de la profunda insatisfacción experimentada por la madre en la relación madre-hijo" (p. 204). La cuestión es entonces en su caso el deslizamiento de este falo de lo imaginario a lo real. Esto es sin duda, lo que nos explica Freud, cuando habla de esa nostalgia del falo originario que empieza a producirse en la niña a nivel imaginario, en la referencia especular al semejante, otra niña u otro niño, y ello recuerda que el hijo será el sustituto del falo. Así, Lacan denomina la "nostalgia del falo".
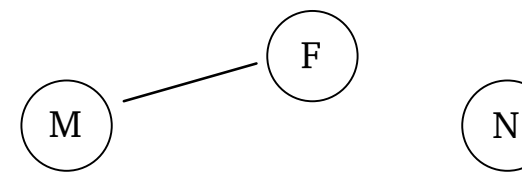
Siguiendo a Lacan (1956), es en lo imaginario, en relación al deseo de falo en la madre, que el niño deberá descubrir este más allá, que denominamos, la falta en el objeto materno. Este es uno de los resultados posibles, en cuanto el niño consigue saturar la situación y puede salir de ahí concibiendo la propia situación como posible, ésta bascula a su alrededor. ¿Qué se encuentra efectivamente en el fantasma de la niña y del niño? Nos dice Lacan, que cuando la situación bascula a su alrededor, la niña encuentra el pene real allí donde está, más allá, en aquel que puede darle un hijo, o sea en el padre. Por no tenerlo como pertenencia, incluso por haber renunciado a él netamente en este terreno, podrá tenerlo como don del padre. El anterior punto de vista de Lacan, es similar a la anotación freudiana, en razón, de que, si la niña entra en el Edipo, lo hace por la relación al falo, y esto de una forma muy simple. Luego el falo sólo tendrá que deslizarse de lo imaginario a lo real por una especie de equivalencia. Este es el mismo término empleado por Freud en su artículo "La diferencia sexual anatómica entre los sexos" (1925), en donde, recordemos, hace la ecuación pene=niño. De esta forma, la niña ya queda introducida en el Edipo.

Para Lacan (1994), todas las anomalías posibles que comporta el alcance de la sexualidad femenina están focalizadas en esta fijación al padre como portador de un pene real, como aquel capaz de dar realmente un hijo. Para la niña esto ya es suficientemente consistente, a fin de cuentas, es la vía de acceso al Edipo, como camino de integración de la posición heterosexual típica. Por ello sostenía Freud, el Edipo en la mujer es mucho más simple, incluso a pesar de los obstáculos en alcanzar la feminidad.

Es a propósito del trabajo de Freud (1932), en particular de los descubrimientos del Edipo y de la castración, que se puede advertir en la mujer una posición que es, por así decirlo, subordinada. El padre es para ella de entrada objeto de su amor, es decir, objeto del sentimiento dirigido al elemento de falta en el objeto, "porque a través de ésta es cómo se ha visto conducida hasta ese objeto que es el padre" (Freud, 1996: 205). Para Lacan (1994), este objeto de amor se convierte luego en dador del objeto de satisfacción, el objeto de la relación natural del alumbramiento. Luego sólo se requiere un poco de paciencia para que el padre sea sustituido al fin por alguien que desempeñara exactamente, el mismo papel de un padre, dándole efectivamente un hijo.

El hecho de tener un hijo provoca en la mujer una gran conmoción, pues es la culminación de un antiguo deseo que se mantenía por mucho tiempo reprimido. Es la solución que brinda Freud (1932), a lo enigmático del deseo femenino, pero con una particularidad, "sólo la relación con el hijo varón brinda a la madre una satisfacción irrestricta, es en general la más perfecta, la 
más exenta de ambivalencia de todas las relaciones humanas" (Freud, 1996: 124). Otro aspecto importante para señalar en este último trabajo de Freud, es la referencia a la libido como la fuerza impulsadora de la sexualidad infantil. En relación a esta libido sexual, se marca una diferencia estructural entre hombres y mujeres, según Freud (1932), sólo hay una libido: la libido masculina. Por ello, se adjudica a la feminidad un alto grado de narcisismo, de suerte que, "para la mujer la necesidad de ser amada es más intensa que la de amar". En otras palabras, el amor en mujeres y en hombres está dado por una diferencia de fase psicológica (p.122).

\section{Sexualidad femenina: la significación fálica y la falta de objeto.}

Como se anotó en el apartado anterior, el Edipo en la niña se ordena de una forma muy simple, en tanto mantiene una relación con el falo; es donde este último sólo tiene que deslizarse de lo imaginario a lo real a través de la equivalencia pene $=$ hijo. Así nos enseña Freud (1932), la niña se introduce en el Edipo. De lo que se trata ahora es de rastrear ésta relación madre-hijo en función de ese significante fundamental que es el falo. De la posición que en relación al significante falo -significante que orienta el deseo de la madre- depende el lugar que ocupe en la estructura, bajo la forma de neurosis, perversión o psicosis.

Lacan en su texto "Las formaciones del inconsciente" (1957), elabora las premisas fundamentales en torno a la sexualidad femenina, a partir de la posición fálica en la mujer. De donde rescata el concepto de deseo, como el término que hace de tapón a esa falta fundamental, que la mujer trata de resarcir por distintas vías. En el apartado titulado "La niña y el falo", Lacan destaca la relación primordial del sujeto-hembra con este legado que es el deseo, en tanto vinculado al deseo del Otro materno. Por ello, el deseo del sujeto no es más que, "la aventura primordial de lo que ocurrió en torno al deseo infantil, [...] o el deseo de ser deseado. Lo que se ha inscrito en el sujeto a lo largo de esta aventura queda ahí, permanente, subyacente" (Lacan, 1989: 279). Por ello al igual que en el sueño el sujeto quiere hacerse reconocer a través de su deseo, y éste -siempre está relacionado con lo que ocurrió en la infancia y fue reprimido-.

Freud en su trabajo "Sobre la sexualidad femenina" (1921), indica que la niña vivencia con su madre unas relaciones bastantes ambivalentes, en donde el deseo de la niña emerge allí como sustitución de la mecánica, de la economía de las gratificaciones y de las agresiones, en su interacción con ese Otro primordial. Esto quiere decir que en un comienzo el ingreso al mundo de la 
cultura se presenta por "la noción fundamental de la dependencia primordial del sujeto respecto del deseo del Otro". Pero el deseo para mantenerse vivo, para no apagarse debe de permanecer suspendido en el inconsciente, en tanto es la suma, la integral, de esa $\mathrm{D}$, del deseo con mayúscula, que Lacan denomina el deseo del Otro.

Para Freud la dialéctica primordial del deseo, no se agota en la relación dual, imaginaria madre - niña tal como él la descubrió; supone un más allá de la madre, implica una relación tercera, debe de incluir la presencia de un personaje, deseado o rival, pero siempre indispensable que es el padre. Por ello, Lacan (1957), ordena el Edipo freudiano a partir de una triada simbólica fundamental: la madre, el niño y el padre. Y, luego agrega un cuarto término, a saber, el falo. La ausencia de la madre o su presencia, le ofrece al niño por la sola introducción de la dimensión simbólica, "la posibilidad o no de ser un niño demandado" (Lacan, 1989: 280).

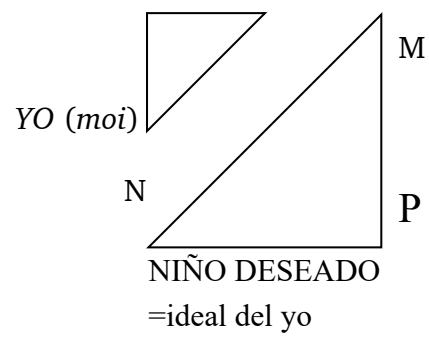

Lacan destaca así el esquema del Edipo Freudiano: el triángulo superior está en el sujeto a nivel de lo imaginario. En donde se destaca, su imagen, $\boldsymbol{i}$. el punto donde se constituye el yo ( $m o i), \boldsymbol{m}$. Y, de forma particular el lugar que corresponde en triada al falo, $\varphi$. La función constituyente del falo en la dialéctica de introducción del sujeto a su existencia y su posición sexual, es impensable deducirla sino se hace de él, el significante fundamental por el cual el deseo del sujeto ha de hacerse reconocer como tal sujeto, trátese del hombre o de la mujer. Cabe recordar con Lacan, que el deseo sea cual sea, tiene en el sujeto una referencia fálica. El deseo del sujeto se articula en la medida en qu|e el propio sujeto ha recibido su significación, en tanto se mutila en relación a una falta fundamental, a partir de esa falta se desprende todo el resto. Esto lo esencial del descubrimiento de Freud. ¿Qué lugar ocupa el falo en la sexuación? Freud destacó desde un comienzo que el falo ocupa un lugar importante en el núcleo edípico; en tanto su uso, a través de los fantasmas del niño guarda relación con las prohibiciones -se trata de la función simbólica del falo-. La diferencia simbólica de los sexos se instaura por que el falo está o no está, y sólo en función de lo que está o no está. Lo que demuestra la experiencia clínica en los análisis de las histerias, es que en la mujer y no sólo 
en el hombre el falo está en el centro. Freud insistió en demostrar como el mismo falo se presenta en el centro de la dialéctica femenina. Así plantea las cosas cuando enuncia que la niña al igual que el niño, desea, en primer lugar, a la madre. Por lo tanto, sólo hay una única forma de desear. Primero la niña se cree dotada de un falo, así como cree que su madre está dotada de un falo.

La anterior descripción es la forma tan particular en que la niña hace su entrada en el Edipo, a través de distintas transferencias de fases instintuales, desde la forma del seno, hasta aquel fantasma fálico, mediante el cual, "se presentan con respecto a la madre en posición masculina" (Lacan,1989:283). En su caso ha de intervenir algo más complejo que el niño para que reconozca su posición femenina. En la elaboración freudiana, el reconocimiento de la posición femenina no sólo se sostiene en nada al principio, sino que resulta supuestamente fallida desde el comienzo. La diferencia simbólica de los sexos antes señalada, marcada en relación al falo que no está, es lo que provoca en la niña una gran decepción; y es allí donde Freud ve el motor de la entrada en su posición femenina. A través de esta decepción es que el complejo de Edipo en la niña desempeña el papel normativo.

Por la vía del disgusto, de la desilusión con respecto a esa fase fantasmática es como la niña es introducida en el complejo de Edipo. Según la analista Lampl de Groot (1927), la niña entra en el Edipo por la fase invertida del complejo. Es a partir del fracaso de la relación con la madre que se le abre el paso a la relación con el padre, con todo lo que a continuación, quedará normativizado por la equivalencia de ese pene, "que ella nunca poseerá, con el niño que en efecto podrá tener y podrá dar en su lugar" (Lacan, 1989: 284). Esta falta en la niña, cuyo nombre fundamental es la castración, Lacan lo escribe con el signo $(-\varphi)$. Freud también situaba el deseo femenino en relación a la falta de ese objeto, llamándolo con una sola palabra: penisneid. Lacan presenta este penisneid de la mujer bajo tres formas distintas, desde la entrada hasta la salida del complejo de Edipo. Veamos estas tres formas:

- Hay penisneid en el sentido del fantasma. Ese anhelo, ese afán tanto tiempo conservado a veces toda la vida - de que el clítoris sea un pene.

- Hay otro sentido cuando el penisneid interviene en el momento en que lo deseado es el pene del padre. Es el momento en que el sujeto se aferra a la realidad del pene allí este se encuentra y ve donde puede ir en busca de su posición. Queda frustrado tanto por la prohibición edípica como debido a la imposibilidad fisiológica.

- Finalmente, en la continuación de la evolución surge el fantasma de tener un hijo del padre, es decir, de tener ese pene bajo una forma simbólica. 
Correlacionadas, con estas tres formas de penisneid, Lacan ordena a propósito del Edipo femenino tres formas de falta de objeto:

- Una "frustración" es imaginaria, pero afecta un objeto perfectamente real. Por eso el hecho de que la niña no reciba el pene del padre es una frustración.

- Una "privación" es completamente real, aunque no afecte sino a un objeto simbólico. En efecto, cuando la niña no obtiene un niño del padre, a fin de cuentas, no se trataba de que lo tuviera. Es incapaz de tenerlo.

- Queda por lo tanto lo correspondiente a la "castración", que amputa simbólicamente al sujeto de algo imaginario. Que en este caso se trate de un fantasma concuerda perfectamente.

En lo concerniente al estudio de la sexualidad femenina cabe recordar que Lacan no concibe la sexuación como un dato en bruto del infantil sujeto, sino como una pregunta. Por lo tanto, en la entrada en el Edipo la niña ingresa justamente con la pregunta que toca con lo real de la castración materna. De modo que Lacan empieza a incluir en su perspectiva el complejo de castración como lo que para el sujeto pone en duda su sexo. Jacques Alain Miller en su escrito "Clínica lacaniana" (2002), indica que, "la sexualidad femenina tiene un papel preponderante en la clínica, aún por encima de la sexualidad masculina" (p.254). Aduce dicha posición en el hecho de que con la "sexualidad femenina" se introdujo de entrada en la falta de objeto en psicoanálisis. En otras palabras, "se denomina sexualidad femenina a una sexualidad cuyo eje es la falta de objeto" (p. 253). Por la anterior vía Freud formuló la primacía del falo y aisló la función decisiva de un objeto que no es uno entre otros, un objeto sin igual que vale tanto para el niño como para la niña. Pero es por la vía de la sexualidad femenina, por el lado de las mujeres como también Lacan hace visible en el campo de la clínica la función del falo.

\section{La sexualidad femenina: el estatuto del niño en la práctica clínica}

El recorrido de Lacan por el seminario "La relación de objeto" (1956), está dedicado explícitamente a los nexos de la sexualidad femenina y la práctica clínica, ello porque la consideración de esta sexualidad permite pensar al infantil sujeto como deseante, esto es, en falta. Luego, la propia clínica de objeto -del objeto freudiano, del objeto perdido- es selectivamente abordada por la sexualidad femenina. En palabras de Miller (2002), "esto traerá consecuencias que valen en este sentido para los dos sexos; a saber, condiciona en particular el estatuto del niño" (p. 254).

¿Cuál es el estatuto del niño en la clínica? Según Miller (2002), el lugar que ocupa el niño en la clínica está correlacionado con los nexos de la sexualidad 
femenina; en los siguientes términos: "Hay entre el falo -que no existe- y el niño una relación de equivalencia o de sustitución" (p. 254). Esta tesis de Lacan, es en el fondo, un argumento de la tesis freudiana, que nos indica que, tratándose de un niño, hay que orientarse por el deseo de la madre. Este es una especie de paradigma con el cual todo niño se debe de topar; en tanto ser sexuado, hay una relación con el falo, ya que es deseado por una mujer que es la madre; y por ello habrá que precisar en cada caso cómo se la arreglo con eso.

Para Lacan (1957), no es propiamente el maternaje lo que requiere atención, sino más bien los avatares de la relación de la madre con el niño; por ello, el personaje de mayor magnitud en la clínica con niños no es la mujer sino la madre. En el escrito sobre "Una cuestión preliminar a todo tratamiento posible de la psicosis" (1955), Lacan, introduce primero, "el estadio del espejo como complemento a la instancia del falo". Ordena así la relación imaginaria: Madre-niño-falo. El falo así articulado queda como referencia de un semblante sin igual; el semblante que por excelencia está ligado a la problemática de la sexualidad femenina. Lacan en su escrito "La niña y el falo" (1956), nos recuerda que la relación del niño con la madre es de lo menos natural que existe, que el maternaje es más una actividad sexual que educativa o sublimada. Y, ello porque entre el niño y la madre lo que se pone en juego obedece a las leyes de una actividad pulsional regulada por un fantasma primordial. Lacan sostiene ésta elaboración a partir de las nociones de pecho bueno y pecho malo de M. Klein (1930), en donde la posición "esquizo-paranoide" y "depresiva" son el resultado de las relaciones edípicas entre la madre y el objeto niño.

Sobre lo anterior, siguiendo a Lacan (1957), se podría articular lo siguiente: es muy difícil no ver que estos datos (posición esquizo-paranoide y depresiva) acusan y profundizan el carácter problemático de las relaciones que se nos presentan como supuestamente naturales, cuando se ven estructuradas por toda una batería significante, articuladas de tal forma que ninguna relación biológica natural podría justificarlas. Por lo tanto, "es ya en el nivel de la experiencia primitiva donde se produce la entrada en escena del falo en la dialéctica del niño" (p. 290). El vínculo con la fase es de naturaleza pulsional. La entrada en la feminidad se produce a partir de una libido que, por su naturaleza, es siempre activa.

Esta transición a la sexuación femenina sólo se produce a partir de una relación con ese significante fundamental que es el falo. Este falo, inviable en la dinámica kleiniana, sólo es concebible si se lo implica de entrada como el significante de la falta, el significante de la distancia entre la demanda del sujeto 
y su deseo. Acá aparece un punto muy importante del tema en tratamiento: La mujer en relación con el falo, sólo se puede relacionar a partir de una operación que Lacan denominó como "la dialéctica de los intercambios" (p.155). Veamos qué significa esto. Para explicar esta dialéctica, Lacan recurre a la esquematización Lévistraussiana, que caracteriza las estructuras elementales del parentesco. Para Levi-Strauss (1969), es un hecho, las mujeres se intercambian entre linajes fundados en el linaje masculino, elegido precisamente por ser simbólico e improbable. Las mujeres, según Lacan (1957), se introducen mediante un intercambio, "el del falo que reciben simbólicamente, y a cambio darán ese hijo que toma para ellas función de Ersatz, de sustituto, de equivalente del falo" (p.155-156). Así es como se introduce en la genealogía simbólica patrocéntrica, la fecundidad natural. Por ello desde el punto de vista de la evolución de la libido sexual, no hay nada natural, que pueda indicar la posición sexuada de un sujeto en la estructura. Para el niño tener ingreso a lo que Lacan denomina la "dialéctica social", sólo puede hacerlo a través de una permutación combinatoria con el significante. En donde "no hay otro deseo del que dependa más estrecha y directamente que el deseo de la mujer, en tanto que es significado precisamente por lo que le falta, el falo" (p. 293).

\section{El niño, un objeto sustituto de la falta materna}

En la evolución del niño hacia el camino de la sexuación se producen diversos tropiezos, muchos accidentes que se encuentran relacionados con ese significante que orienta el deseo de la madre, a saber, el falo. Por lo tanto, cabe recordar, que el niño no está jamás sólo con la madre, delante suyo está el falo. De la manera tan particular en que se relacione en niño con el falo depende su posición en la estructura: bien puede tomar la forma de la neurosis, la perversión o incluso la fobia.

Sobre este "estar a solas", se pueden colegir distintas posturas en relación al deseo del infantil sujeto. Lacan nos enseña a través de su análisis del caso Hans (1910), una puntualización clínica muy importante: ¿Cómo establecer la diferencia entre demanda y deseo en el caso del pequeño Hans? ¿Qué tipo de demanda es la que establece el niño? Según Lacan (1956), la demanda del niño, podría ser - pero no es - permanecer con la madre. Lacan pone esto en evidencia desde la conversación del pequeño Hans, en un determinado momento que dice que quiere estar solo con su amiga Mariedl, ganz allein mit der Mariedl. Y, preguntándole si quería estar con ella, responde: "que quería estar sólo con Mariedl". Lacan subraya el "solo con" como el centro del problema; del vínculo del pequeño Hans con su madre. El niño no solamente quería estar a solas con la madre, sin el padre, sino también, "sin la sombra 
del falo que perturba sus relaciones". Su demanda no es quedarse sólo con su madre, pues hay precisamente un momento en que eso se sustenta para el niño, porque en la relación con ella, él se ve insuficiente para colmarle el agujero. Según Lacan toda la cuestión gira, al contrario: ¿Cómo no quedar sólo con la madre? La cuestión la elabora el niño, no bien descubre que es insuficiente en cuanto a la falta. Primero, porque entra en juego su propio pene, que ahora cobra vida, y que, en cierto modo, lo desfaliciza. Pues al enseñárselo a su madre, ella dice "es una porquería". Esta es tal vez la palabra más decisiva. En segundo lugar, está el nacimiento de su hermana, la pequeña Hanna. Con esos dos elementos ya no puede quedarse "sólo con la madre", porque hay una distancia y una amenaza de devoración.

Para Lacan (1956), si bien la intrusión real del otro niño en la relación del niño con la madre, es en verdad adecuada para precipitar determinado momento crítico, determinada angustia decisiva; no obstante, no duda en resaltar ese "completamente sólo, con", porque parte de una situación real, el niño nunca está sólo con la madre. Todo el progreso que puede conocer la relación aparentemente dual del niño con la madre se encuentra, en efecto, en el eje que Freud mantuvo con firmeza hasta el final en lo concerniente a la sexualidad femenina: "el niño no interviene sino como sustituto, como compensación, en suma, en una referencia, sea cual sea, a lo que le falta esencialmente a la mujer" (p.243).

Por eso no está nunca completamente sólo, ganz allein, con la madre. La madre se sitúa, y así va conociéndola poco a poco el niño, como marcada por está falta fundamental que ella misma trata de colmar, y con respecto a la cual el niño le aporta sólo una satisfacción que se podría llamar, provisionalmente, sustitutiva. Por ello Freud decía que el niño no era más que un sustituto: "Un Ersatz, no es la cosa misma. Hay eine Gleichung- una equivalencia, una ecuación -: Niño igual a falo" (Miller, 2002: 420).

$$
\mathrm{NIÑO}=\varphi
$$

¿Pero si el deseo de la madre no se colma con el hijo de que otra manera se puede lograr? Acá interviene entonces una dinámica y una relación distinta, entorno a los nexos de la sexualidad femenina y la falta de objeto. Si el niño no es suficiente porque es tan sólo un sustituto, la respuesta debe de hallarse en un más de la metáfora del niño. Es importante acá, recordar con Lacan, que las madres antes que todo son "mujeres", es por esta vía alterna donde se puede hacer obstáculo al objeto niño, que no alcanza a cubrir toda la instancia de la falta femenina en términos fálicos. 


\section{A modo de conclusión}

A lo largo del recorrido teórico de la obra freudiana el estudio de la sexualidad femenina deja muchos puntos enigmáticos, y esto porque el Edipo en la niña se concibe de manera contraria al Edipo en el niño. Freud nos hace saber a través de sus casos clínicos que, algo de lo no concluido es específico de la sexualidad femenina. En términos estructurales, por ejemplo, podría decirse que "la Joven homosexual" (1920), muestra como ninguna que el falo no tiene el mismo valor para las mujeres que para los hombres y, a su vez, indica la labilidad de las identificaciones en las mujeres.

El estudio de la "sexualidad femenina" (1921), plantea una simetría entre hombres y mujeres respecto de la premisa fálica. Freud propone para la mujer tres orientaciones del desarrollo: una la inhibición sexual o la neurosis, la otra la alteración del carácter en el sentido de masculinidad, y la tercera la feminidad normal; vía la ecuación simbólica pene=hijo. Este deseo de tener un hijo del padre, es una especie de compensación que trata de resarcir el daño hecho por la madre de no haberla dotado con el miembro masculino; se redimensiona entonces la relación con la madre, que ahora resulta ser lo primario, en tanto el Edipo es secundario. Una vez teorizada la envidia del pene, la maternidad será uno de los modos de resolver ésta falta en términos fálicos. Otro modo será la vía del amor, en donde la mujer buscará un partenaire con pene, otra opción de colmar la falta. Y, una tercera salida será falicizar el propio cuerpo.

De lo anterior se puede deducir que la envidia del pene -penisneid - toma ahora un estatuto estructural. Si la exigencia del falo no se resuelve vía la maternidad, ni vía la elección de un partenaire con pene, tampoco se soluciona falicizando el propio cuerpo. Entonces, esto nos indica que ni por la vía del tener, ni por la vía del ser, se puede responder para colmar esa falta fundamental, que queda como resultado de la operación de la castración en la mujer.

Lo anterior explica en parte el desconcierto de Freud frente al enigma de la feminidad. Pero a partir de sus hallazgos algo si queda bien claro: ésta falta estructural en la mujer no se resuelve por la vía del falo. Por ello concluye su trabajo para ésta época - 1932 - abordando una pregunta capital: ¿Qué demanda la niña a su madre? Esta demanda será el eje de la relación con ese Otro primordial. Como afirma Lacan, ésta demanda es siempre demanda de amor.

Finalmente, queda un punto para tratar, a partir de las tres orientaciones que propone Freud para el desarrollo de la mujer, es lícito preguntarse entonces por el nexo: neurosis infantil y sexualidad femenina. ¿Cuál es el estatuto 
del niño en la práctica clínica?, y ¿Qué relación guarda el deseo de la madre con la posición del sujeto en la estructura? Para resolver estos interrogantes es necesario evocar el trabajo de Lacan (1955), "en los esquemas del texto sobre la psicosis se escribe DM (el deseo de la madre) no sólo el deseo metonímico, sino el que tiene un objeto simbolizado por el falo y también, en el fondo, el deseo como tal" (Miller, 1998: 420). Este deseo es, por definición y estructuralmente, insatisfecho. Lacan nos enseña en su seminario "La relación de objeto" (1956), que como este deseo no puede ser satisfecho, sólo se trata de engañarlo. Así tenemos que, lo esencial en la práctica clínica, lo fundamental, es que, "el niño se coloque en el lugar de un objeto engañador". Porque si bien, al deseo no se le puede poner la mano encima, hay que tratar entonces de engañarlo (Miller, 2002: 254).

Así, en un juego parecido al Fort-da, pero invertido se debe establecer ese vínculo fundamental madre-hijo. Se dice invertido, porque acá el papel principal lo debe de ocupar el niño, en tanto muestra la habilidad para acercarse y alejarse del deseo materno. Es una clínica del niño engañador, porque este es capaz de representar un papel donde lo fundamental con respecto al deseo de la madre es no- satisfacerlo. De la forma tan particular como se mueva el niño, esto es, como se movilice frente al señuelo del deseo materno, dependerá su posición en la estructura: así, por ejemplo, el sujeto como niño, "puede confundirse con esta imagen fálica o encontrarse en déficit con respecto a ella, o incluso asimilarse con la madre" (Miller, 2002: 255).

Para sintetizar: Lacan complementa la teoría del narcisismo a partir de una elaboración del "estadio del espejo" (1949), la cual es repensada en relación con el falicismo. El estadio del espejo no se podría comprender sin el agregado de la instancia del falo. Pero así mismo, Lacan observó la insuficiencia del estadio del espejo más el falo y consideró que este ternario para equilibrarse, para estabilizarse, exigía la introducción de un cuarto elemento, la función normativizadora del padre. Si bien el padre no le ofrece todas las garantías al niño con su "función", le abre todo un abanico de posibilidades para no ahogarse en el deseo de la madre (DM).

Siguiendo a Miller (2002), podría decirse que a este niño que no sabe si debe confundirse con esta imagen (la del falo), o con la de la madre y que vacila en este palacio de espejismos, en donde se le precipitó con alivio en la función paterna. Esta función que dicta la ley al falo imaginario aportaría el alivio de sacarlo del "soy o no soy," de esta problemática de identificación alternante, por la promesa de un tener. En estos términos la función del padre parece ser de un "tendrás", y promete de este modo al niño la investidura fálica o, en fin, "autoriza un ejercicio legítimo del órgano al sujeto masculino" (p.255). 
También es importante recalcar que, no basta con la función paterna, ésta quizás no sea suficiente para regular el deseo de la madre (DM). Esta posición le permitió a Lacan una relectura paradójica de la posición anaclítica, de la cual hace la posición erótica misma en el hombre, "que le asegura que, como depositario del falo, la mujer depende de él". En el fondo, al santificar la función del padre, "tal vez se desconoce que, en verdad, Lacan acentúa los defectos de dicha función" (Miller, 2002: 255).

Sí Lacan se dedica al estudio de la perversión es para enseñarnos que su imperio se extiende bastante lejos en la sexualidad masculina, y con ello marca la multiplicidad, la inventiva, el vigor, de las soluciones perversas aportadas al ternario imaginario. De este modo se distingue en Lacan (1956), una muy fina clínica diferencial de las perversiones que descansa justamente en la presencia del semblante fálico en el estadio del espejo madre-niño. Esto tiene consecuencias porque incluso en su lectura del pequeño Hans, Lacan duda mucho de que la paternidad no se haya introducido sólo de manera imaginaria.

\section{Referencias}

Alfonso, I. (1995). Técnicas de investigación bibliográfica. Caracas: Contexto Ediciones.

Cottet, S. (1998). Freud y el deseo del psicoanalista. Buenos Aires: Editorial Paidós.

Freud, S. (1996). Manuscrito N. Carta 69. En: Obras Completas, Vol. 1. Buenos Aires: Amorrortu Editores.

Freud, S. (1996). Tres ensayos de teoría sexual. En: Obras Completas, Vol. 7. Buenos Aires: Amorrortu Editores.

Freud, S. (1996). Fragmento de análisis de un caso de histeria. En: Obras Completas, Vol. 7. Buenos Aires: Amorrortu Editores.

Freud, S. (1996). Carácter y erotismo anal. En: Obras Completas, Vol. 9. Buenos Aires: Amorrortu Editores.

Freud, S. (1996). La moral sexual cultural y la nerviosidad moderna. En: Obras Completas, Vol.9. Buenos Aires: Amorrortu Editores.

Freud, S. (1996). Análisis de la fobia de un niño de cinco años. En: Obras Completas, Vol. 10. Buenos Aires: Amorrortu Editores.

Freud, S. (1996). A propósito de un caso de neurosis obsesiva. En: Obras Completas, Vol. 10. Buenos Aires: Amorrortu Editores.

Freud, S. (1996). El tabú de la virginidad. En: Obras Completas. Vol. 11. Buenos Aires: Amorrortu Editores. 
Freud, S. (1996). Un caso de paranoia que contradice la teoría psicoanalítica En: Obras Completas. Vol.14. Buenos Aires: Amorrortu Editores.

Freud, S. (1996). Sobre la psicogenesis de un caso de homosexualidad femenina. En: Obras Completas. Vol. 18. Buenos Aires: Amorrortu Editores.

Freud, S. (1996). Algunas consecuencias psíquicas de la diferencia anatómica entre los sexos. En: Obras Completas. Vol.19. Buenos Aires: Amorrortu Editores.

Freud, S. (1996). El sepultamiento del complejo de Edipo. En: Obras Completas. Vol.19. Buenos Aires: Amorrortu Editores.

Freud, S. (1996). La organización genital infantil. En: Obras Completas. Vol. 19. Buenos Aires: Amorrortu Editores.

Freud, S. (1996). Sobre la sexualidad femenina. En: Obras Completas. Vol.21. Buenos Aires: Amorrortu Editores.

Freud, S. (1996). La feminidad. En: Obras Completas. Vol. 22. Buenos Aires: Amorrortu Editores.

Hamon, M.C. (1995). ¿Por qué las mujeres aman a los hombres? Y no a su madre. Barcelona: Paidós Ibérica, S.A.

Klein, M. (1989). Posición esquizo-paranoide. En: Obras Completas (amor, culpa y reparación) 1921-1945. Segunda Edición. Barcelona: Editorial Paidós.

Lacan, J. (2007). De una cuestión preliminar a todo tratamiento posible de la psicosis. En: Escritos 2. México: Editorial Siglo xxi.

Lacan, J. (2009). Del Trieb de Freud y el deseo del psicoanalista. En: Escritos 2. México: Editorial Siglo xxi.

Lacan, J. (2007). Observación sobre el informe de Daniel Lagache. En: Escritos 2: México: Editorial Siglo XXI.

Lacan, J. (2007). Posición del inconsciente. En: Escritos 2. México: Editorial Siglo XXI.

Lacan, J. (2007). El estadio del espejo como formador de la función del yo (je) tal como se nos revela en la experiencia psicoanalítica. En: Escritos 1. México: Editorial Siglo XXI.

Lacan, J. (1988). Conferencia en Ginebra sobre el síntoma. En: Intervenciones y textos 2. Buenos Aires: Editorial Manantial.

Lacan, J. (1988). Dos notas sobre el niño. En: Intervenciones y textos 2. Buenos Aires: Editorial Manantial.

Lacan. J. (1984). Las psicosis. Libro 3. Barcelona: Editorial Paidós. 
Lacan, J. (1967). Proposición del 9 de octubre de 1967 sobre el psicoanalista de la escuela. Paris: Inédito.

Lacan, J. (1989). Los cuatro conceptos fundamentales del psicoanálisis. Seminario 11. Buenos Aires. Editorial Paidós.

Lacan, J. (1991). La lógica del fantasma. Seminario 14. Buenos Aires: Inédito.

Lacan, J. (1994). La relación de objeto. Seminario 4. Buenos Aires: Editorial Paidós.

Lacan, J. (1994). La niña y el falo. En: La relación de objeto. Seminario 4. Buenos Aires: Editorial Paidós.

Lacan, J. (1999). Las formaciones del inconsciente. Seminario 5. Buenos Aires: Editorial Paidós.

Lacan, J. (2008). El reverso del psicoanálisis. Seminario 17. Buenos Aires: Editorial Paidós.

Laurent, E. (1999). Hay un final de análisis para niños. Buenos Aires: Editorial Diva.

Miller, J. A. (1998). Recorrido de Lacan. Buenos Aires: Editorial Manantial.

Miller, J. A. (1988). Elucidación de Lacan. Charlas brasileras. Buenos Aires: EOLPaidós.

Miller, J. A. (1988). El síntoma y el cometa. En: El síntoma Charlatán. Barcelona: Editorial Paidós.

Miller, J. A. (1989). El niño, entre la mujer y la madre. En: Carretel número 1. Buenos Aires.

Miller, J. A. (2002). De la naturaleza de los semblantes. Buenos Aires: Editorial Paidós.

Miller, J. A. (2018). Del síntoma al fantasma. Y retorno. (1982-1983). Buenos Aires: Editorial Paidós.

Miller, J.A. (1998). El síntoma y el cometa. En: El síntoma Charlatan. Barcelona: Editorial Paidós.

Pérez, J.F. (1998). Elementos para una teoría de la lectura. Revista Colombiana de Psicología, 7: 239-244, DOI: 10.15446/rcp

Recalde, M. (2001). El Edipo un interrogante freudiano. En: Del Edipo a la sexuacion. Buenos Aires: Editorial Paidós.

Rojas Crotte; I.R. (2011). Elementos para diseño de técnicas de investigación: una propuesta de definiciones y procedimientos en la investigación científica. Recuperado de http://www.redalyc.org/pdf/31121089006.pdf 
Silvestre, M. (1987). La neurosis infantil según Freud. En: Mañana el psicoanálisis. Buenos Aires: Editorial Paidós.

Solano, E. (1998). Actualidad de la práctica psicoanalítica. En: Psicoanálisis con niños y púberes. Buenos Aires: Editorial Labrado.

Solano, E. (1998). El síntoma en el niño. En: ¿Cómo cura el psicoanálisis? Bogotá: NEL-Serie Bitácora, vol. 1.

Strauss, L. (1969). Las estructuras elementales de parentesco. Barcelona: Ediciones Paidós Ibérica, S.A.

Winnicott, D.W. (1993). Los procesos de maduración y el ambiente facilitador: estudios para una teoría del desarrollo emocional. Buenos Aires: Editorial Paidós. 